\title{
Ice Core Young Scientists workshop
}

Pascal Bohleber', M. Cavitte' ${ }^{2}$ B. Koffman³ ${ }^{3}$ B. Markle ${ }^{4}$, P. Pavlova ${ }^{5}$, M. Winstrup ${ }^{6}$ and H. Winton ${ }^{7}$

Hobart, Australia, 6 March 2016

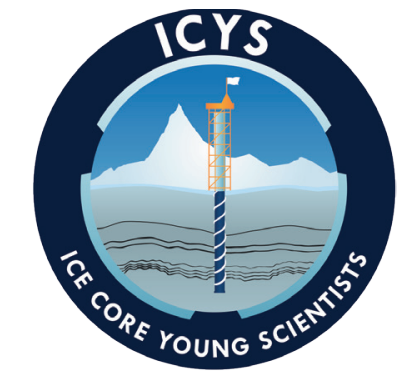

Ice Core Young Scientists (ICYS) held a highly successful one-day workshop for early-career researchers (ECRs) in conjunction with the IPICS 2016 conference in Hobart, Australia. Over 85 ECRs attended the event, equivalent to about $40 \%$ of the IPICS conference delegation. In addition to providing professional development, the workshop offered a chance for ECRs to get to know each other before the week-long conference began.

The workshop kicked off with a plenary lecture by Nerilie Abram of the Australian National University, asking the question "Why do we need more paleoclimate records from Antarctica?" Nerilie presented research currently in preparation by the PAGES $2 k$ Network, showing that climate models currently do not accurately represent the climate in the Southern Hemisphere. She argued for additional ice-core records from Antarctica and for improved integration of ice-core and other paleoclimate proxy data.

The plenary was followed by a lively panel discussion on the future of ice-core science. Eight panelists shared their views on what and where the next big ice-core project should be, and what major questions the community can try to address using ice cores in the future. Major themes coming out of the discussion included: (a) integrating data from multiple ice cores, such as the work by the PAGES Antarctica2k community; (b) filling in the latitudinal gap of paleoclimate records between the poles and taking advantage of other types of climate proxy records; (c) enhancing the interaction with climate modelers, oceanographers, and biologists using ice cores to answer non-climate questions; and (d) advancing technologies, such as rapid-access drilling and in situ analysis down boreholes. Major questions centered on improving predictions for future climate, especially in regard to sea-level rise, and understanding the role of Antarctica in the climate system. During the IPICS conference closing session, ICYS provided the broader ice-core community with an ECR perspective on the future of ice-core science.

The ICYS workshop included breakout discussions focused on topics of great importance to ECRs, but which are rarely taught in formal settings. Session topics included "How to get your research funded as an ECR", "Leadership techniques and being a principal

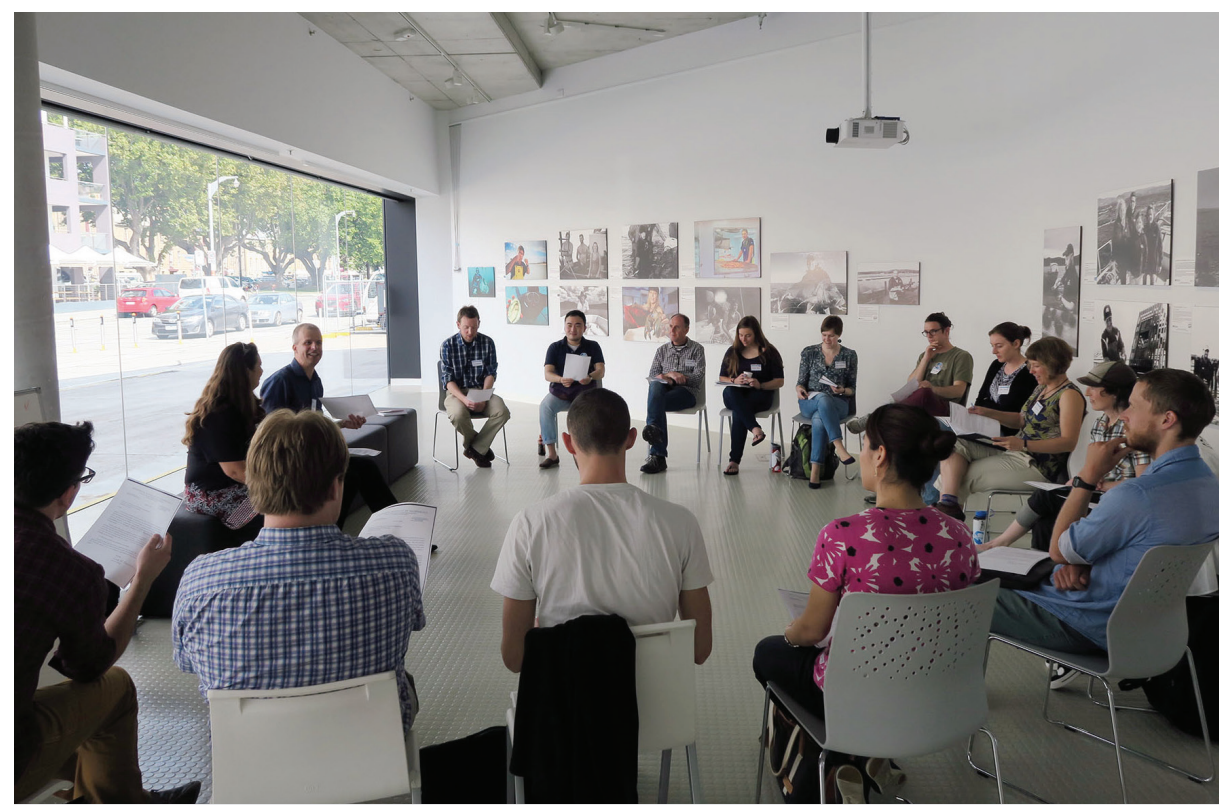

Figure 1: Discussion group "science, family and equality: negotiating the ECR career path".

investigator" and "Initiating international collaborations". Each breakout group was facilitated by a mid-career scientist who shared his or her expertise and experience in these areas. We were also lucky to have Michael White, an editor at Nature, discuss issues around authorship.

Our final plenary session was facilitated by Heidi Roop, of the Science and Society research group at Victoria University of Wellington, New Zealand. Heidi shared insights on how to communicate more effectively with the public. We learned that "knowledge building" efforts, such as having community meetings and developing citizen science initiatives, are most effective in getting the public to understand, appreciate, support, and critically become involved with the science we do. We were able to fold these ideas into short outreach videos, called FrostBytes, which were produced at the end of the workshop. They will serve as a valuable resource for outreach and engagement, and are publicly available on the Climate and Cryosphere (CLiC) website.

PAGES generously supported six travel packages for ECRs from developing countries to attend the workshop. Travel support for ECR attendees was also provided by the US National Science Foundation, the IPICS 2016 conference sponsors, the EPICA Descartes Prize, and the West Antarctic Ice Sheet Divide ice core program. Lunch was kindly supported by CLiC.

This workshop, the first of its kind, successfully built a more cohesive international community of ECRs in ice-core sciences and provided those researchers with information and skills useful to their developing careers - the primary goals of ICYS. Many attendees remarked that simply meeting fellow ECRs before the main meeting improved their conference experience and sense of involvement in the community.

\section{AFFILIATIONS}

'Climate Change Institute, University of Maine, Orono, USA

Institute for Geophysics, University of Texas at Austin USA

${ }^{3}$ Department of Earth Sciences, Dartmouth College, Hanover, USA

${ }^{4}$ Earth \& Space Sciences, University of Washington, Seattle, USA

${ }^{5}$ Paul Scherrer Institut, Villigen, Switzerland

${ }^{6}$ Centre for Ice and Climate, University of Copenhagen, Denmark

${ }^{7}$ British Antarctic Survey, Cambridge, United Kingdom

\section{CONTACT}

ICYS Executive Committee: icecoreys@gmail.com 